\title{
ETIKA BISNIS DAN ENTREPRENEURSHIP DALAM PEMBANGUNAN EKONOMI BALI: DALAM PERSPEKTIF HINDU
}

\author{
Oleh: \\ Putu Krisna Adwitya Sanjaya \\ Fakultas Ekonomi Universitas Hindu Indonesia \\ Denpasar \\ krisnasanjaya50@yahoo.co.id
}

\begin{abstract}
The Government of Bali focuses on accelerating development to improve peoples welfare. Regional economic development is an activity where local governments and communities manage existing resources and form partnerships between local governments and the private sector to create new jobs and stimulate the development of economic activities within the region, in support of economic business need to pay attention to the values ethics consistent with religious teachings. The inhabitants of Bali including its entrepreneurs are supporters of a culture that is imbued with religion. As a supporter of culture, their role is crucial in the growth and development of religious life, culture and the activity of economic development. The main pattern of Balinese development establishes the culture that complete the Hindu spirit as the basic capital of regional development. There are two interrelated things between business economics and ethics, business can not be separated by the social culture where ethics is implemented. A business activity must be carried out with the ethical values prevailing in the business community.
\end{abstract}

Keywords: Business Ethics, Entrepreuner, Hinduism and Economic Development

\begin{abstract}
Abstrak
Pemerintah Bali fokus melakukan akselerasi pembangunan untuk meningkatkan kesejahteraan masyarakat. Pembangunan ekonomi daerah merupakan suatu aktivitas dimana pemerintah daerah dan masyarakatnya mengelola sumber daya yang ada dan membentuk partnership antara pemerintah dengan swasta untuk menciptakan lapangan kerja baru dan merangsang perkembangan kegiatan ekonomi dalam wilayah tersebut, dalam menunjang aktivitas ekonomi (bisnis) perlu memperhatikan nilai-nilai etika yang sesuai dengan ajaran agama. Penduduk Bali termasuk para entrepreneurnya merupakan pendukung kebudayaan yang dijiwai oleh agama. Sebagai pendukung kebudayaan, peran mereka sangat menentukan dalam tumbuh dan berkembangnya kehidupan agama, kebudayaan maupun akititas pembangunan ekonomi. Pola pokok pembangunan Bali menetapkan kebudayaan yang bernafaskan spirit Hindu sebagai modal dasar pembangunan daerah. Ada dua hal yang saling terkait antara ekonomi bisnis dan etika, bisnis tak dapat dipisahkan dengan sosial budaya dimana etika diimplementasikan. Suatu kegiatan bisnis wajib dilakukan dengan nilai etika yang berlaku dalam masyarakat bisnis.
\end{abstract}

Kata Kunci: Etika Bisnis, Entrepreuner, Hindu dan Pembangunan Ekonomi 


\section{PENDAHULUAN}

Di era milenial seperti saat ini, dunia bisnis tumbuh dan berkembang dengan sangat pesat, hal ini ditandai dengan maraknya aneka ragam jenis produk maupun derifatifnya yang membanjiri pasar. Dalam struktur ekonomi saat ini, bisnis memainkan peran yang sangat strategis dalam mentransformasi struktur perekonomian, karena bisnis memberi pesan tentang apa yang dihendaki oleh masyarakat. Di tengah semakin ketatnya persaingan pasar, para entrepreneur (pelaku usaha) tampak lebih memilih jalan pintas dengan menininggalkan value ethics asalkan keberlangsungan usahanya terselamatkan, daripada menjunjung tinggi etika namun usaha (bisnis) mengalami kebangkrutan (Hulaimi, 2017).

Persoalan pembentukan etika dalam berbagai disiplin ilmu menjadi sangat urgent untuk dikaji manakala dunia harus dihadapkan pada beragam problematika yang mengarah pada moralitas. Munculnya fenomena ketakutan akan persaingan bisnis di zaman global mengakibatkan pelaku ekonomi menghalalkan segala cara untuk memenangkan persaingan (Adhiputra, 2014). Ada dua hal yang saling terkait antara ekonomi bisnis dan etika, bisnis tak dapat dipisahkan dengan sosial budaya dimana etika diimplementasikan. Suatu kegiatan bisnis wajib dilakukan dengan dengan etika maupun norma-norma yang berlaku dalam masyarakat bisnis. Etika dan norma-norma tersebut dipergunakan agar para entrepreneur tidak melanggar aturan yang telah ditetapkan dan bisnis yang dilakukan mendapat berkah dari Tuhan Yang Maha Esa.

Sekitar era 1960-an, istilah business ethics maupun ethics in business di Amerika Serikat menjadi suatu hal yang kontroversial. Lektur tentang nilai-nilai keagamaan tertentu ikut berperan dalam kehidupan sosial ekonomi masyarakat tertentu, telah banyak dilontarkan dalam masyarakat ekonomi, seperti oleh seorang sosiolog berkebangsaan Jerman Max Weber (1864-1919) dalam karya monumentalnya yang berjudul The Protestant Ethic and Spirit of Capitalism, Weber berupaya menjelaskan mengapa kapitalisme modern berkembang di Eropa dan Amerika, tetapi tidak di wilayah lain. Dalam penjelasannya, Weber mengemukakan bahwa di Eropa Barat telah terjadi suatu peristiwa keagamaan dan ideologis yang unik, yaitu reformasi Protestan. Peristiwa itu telah melahirkan nilai universalitas dan kebutuhan untuk berprestasi. Aliran Calvinis (suatu sekte dalam Protestan), memandang kerja sebagai tugas suci bukan sekedar untuk mencukupi kebutuhan sehari-hari. Paham ini juga mengajarkan bahwa keberhasilan individu dalam mengumpulkan harta benda maka akan mendapat keselamatan. Semangat kerja keras dikalangan Calvinis itu menyebabkan mereka muncul sebagai entrepreneur yang tangguh dan selalu menggunakan profit untuk mengakumulasi capital. Entrepreneur inilah yang kelak menjadi backbone sistem ekonomi kapitalis di wilayah tersebut. Di pihak lain, Weber mengemukakan bahwa nilai-nilai agama timur, berbeda dengan Protestanisme yang justru menghambat tumbuhnya kapitalisme. Dalam karyanya The Religion of China: Confucianism and Taoism, Weber berpandangan bahwa etika Konfusius merupakan salah satu faktor penghambat tumbuhnya kapitalisme nasional di China. Beberapa studi yang dilakukan di Asia menemukan kenyataan menolak teori Weber. Geertz (1977) melakukan studi di Jawa Timur, menyimpulkan adanya similaritas antara nilai-nilai yang dianut oleh golongan modernis Islam di Indonesia dengan etika Protestan yang melahirkan semangat kapitalisme, yaitu bekerja keras, tekun, hemat dan rasional, hal ini juga didukung oleh Bellah dalam Gorda (1995) yang menemukan bahwa bagaimana agama Tokugawa mengandung rational values yang menjadi pijakan fundamental bagi keberhasilan modernisasi pembangunan perekonomian Jepang.

Provinsi Bali merupakan bagian integral dari Negara Kesatuan Republik Indonesia dengan luas wilayah 5.636,66 km², atau sekitar 0,29 persen dari keseluruhan wilayah Indonesia yang melakukan transformasi struktur ekonomi untuk mengakselerasi pembangunan perekonomian. Pembangunan Ekonomi Provinsi Bali dalam kurun waktu sewindu terakhir boleh dikatakan lumayan berhasil jika dilihat dalam indikator statistik makro ekonomi. Keberhasilan itu terlihat antara lain, dari laju pertumbuhan rata-rata perekonomian dalam kurun waktu tersebut di level 6,42 persen per tahun jauh melampaui capaian pertumbuhan ekonomi nasional yang bertengger di kisaran 5,61 persen 
per tahun (BPS Provinsi Bali, 2017). Di lain pihak bila dilihat laju pertumbuhan penduduk secara average mengalami penurunan. Dalam kurun waktu dari tahun 2010 sampai dengan tahun 2016 laju pertumbuhan penduduk Bali sebesar 1,21 persen lebih rendah dari capaian nasional sebesar 1,36 persen. Bila dilihat dari indeks kemiskinan dalam empat tahun terakhir (2014-2017) nilai mean penduduk miskin di Bali adalah sebesar 4,57 persen sedangkan nasional berada di level 10,52 persen. Penurunan penduduk miskin tersebut juga berkorelasi positif terhadap Indeks Pembangunan Manusia (IPM) yang selalu mengalami peningkatan dalam empat tahun terakhir, secara rata rata sebesar 73,42 melebihi capaian nasional yakni sebesar 70,11 kondisi tersebut mengkapitalisasi laju pertumbuhan Produk Domestik Regional Bruto (PDRB) Provinsi Bali secara average di angka 6,16 persen per tahun.

Melalui konsep trickle down effect dipercaya bahwa transformasi ekonomi memberi konstribusi yang signifikan dalam mengakselerasi pembangunan ekonomi dimana core nya adalah penciptaan lapangan kerja termasuk mencetak entrepreneurship yang seluas-luasnya dan mampu bersaing secara kompetitif. Penduduk Bali termasuk para entrepreneurnya merupakan pendukung kebudayaan yang bernafaskan agama Hindu. Sebagai pendukung kebudayaan, peran mereka sangat menentukan dalam tumbuh dan berkembangnya kehidupan agama, kebudayaan maupun akititas pembangunan perekonomian di Bali. Pola pokok pembangunan Daerah Bali yakni menetapkan kebudayaan yang bernafaskan sipirit agama Hindu sebagai salah satu modal dasar pembangunan daerah. Menarik untuk dicermati adalah bagaimana dan adakah konsep Hindu yang menawarkan etika bisnis bagi pelakunya (khususnya para entrepreneur) sebagai lokomotif pembangunan ekonomi di Bali.

\section{PEMBAHASAN}

\subsection{Kerangka Dasar Agama Hindu}

Pustaka Suci Veda merupakan sumber dari agama Hindu. Ditinjau dari sudut sumbernya, veda terbagi dalam dua bagian besar, yakni Veda Sruti dan Veda Smrti ( Manavadharmasastra II.10 dan Sarasamuccaya, sloka 37). Veda Sruti terdiri dari empat himpunan veda yakni Reg veda, Samaveda, Yayurveda dan Atharvaveda. Veda Smrti adalah himpunan ajaran-ajaran Hindu yang memuat interpretasi atas wahyu Tuhan yang tertulis dalam Veda Sruti, yang termasuk ke dalam kelompok Veda Smrti ini adalah Ramayana, Mahabharata, Bhagawadgita, Sarasamuccaya dan Manavadharmasastra.

Selain berdasarkan sumber, Pustaka Suci Veda juga dapat dibagi berdasarkan isinya, yakni Jnanakanda yang memuat tentang hal-hal terkait tattwa atau filsafat dan Karmakhanda yang mengulas tentang tata susila dan upacara Abdurrahman dalam Gorda (1995). Veda merupakan ajaran suci yang diajarkan secara lisan. Penulisan Veda dilakukan sekitar abad ke lima sebelum masehi. Umat Hindu Bali memperingati turunnya Veda setiap 210 hari yang jatuh pada hari Sabtu Umanis Wuku Watugunung yang dikenal dengan hari Raya Saraswati. Pada hari raya ini umat Hindu berdoa di tempat suci untuk memanjatkan syukur atas kemurahan hati Sang Hyang Widhi Wasa yang telah berkenaan mewahyukan ajaran-ajaran suci bagi umat-Nya.

Ajaran agama Hindu dibangun diatas tiga kerangka dasar yang saling terkoneksi satu dengan lainnya dalam suatu unifikasi yang bulat dan utuh, yakni tattwa, tata susila dan upacara. Tattwa menguraikan secara metafisis aspekaspek filosofis dari Panca Sraddha, hubungan manusia dengan Tuhan, hubungan manusia dengan sesama dan hubungan manusia dengan alam. Kerangka dasar yang kedua adalah tata susila, menguraikan ajaran tentang perbuatan mana yang baik (subhakarma) dan mana yang buruk (asubhakarma) menurut norma- norma agama Hindu. Kerangka dasar yang ketiga adalah upacara, yaitu rangkaian kegiatan umat Hindu dalam upaya menghubungkan diri dengan Tuhan, upacara dikejewantahkan berupa persembahan atau korban suci (yajnya) dan merupakan manifestasi konkret dari agama. Diatas ketiga kerangka dasar ini, umat Hindu mempelajari, menghayati, memahami serta menjalankan ajaran agamanya dalam kehidupan.

Seluruh ajaran agama Hindu tercakup dalam Panca Sradha (Lima Keyakinan), yakni keyakinan terhadap Sang Hyang Widhi Wasa, Keyakinan terhadap Atman, Keyakinan terhadap Karmaphala, Kenyakinan terhadap Punarbhawa dan Keyakinan terhadap manunggalnya Atman dengan Brahman. 


\subsection{Paradigma Pembangunan Ekonomi Daerah : Pendekatan Teoritik}

Pembangunan ekonomi merupakan suatu daya dan upaya yang terencana, terstruktur dalam mengelola segenap resources untuk meningkatkan kesejahteraan masyarakat. Sumber daya relatif terbatas jumlahnya bahkan diantaranya tidak dapat diperbaharui atau bertambah dengan cepat sedangkan kebutuhan manusia terus meningkat jumlah dan ragam jenisnya. Kebutuhan tersebut tidak selalu dapat dipenuhi oleh sebuah daerah karena keterbatasan kepemilikan sumber daya (Rahyuda, 2003). Secara alamiah telah terbangun korelasi ekonomi antar daerah yang saling terkait dan bergantung bahkan dalam skala internasional. Oleh karena itu, pembangunan ekonomi dalam kerangka pengembangan wilayah memberikan perhatian kepada konektifitas antar ruang desa dan kota dengan regional, nasional maupun internasional yang dilandasi oleh hakekat keterkaitan (linkages) dan ketergantungan (dependencies).

Pembangunan ekonomi daerah merupakan suatu aktivitas dimana pemerintah daerah dan masyarakatnya mengelola sumber daya yang ada dan membentuk partnership antara pemerintah daerah dengan sektor swasta untuk menciptakan lapangan kerja baru dan merangsang perkembangan kegiatan ekonomi dalam wilayah tersebut. Permasalahan pokok dalam pembangunan ekonomi daerah terletak pada kebijakan-kebijakan pembangunan yang didasarkan atas karakteristik daerah yang bersangkutan (endogenous) dengan menggunakan potensi human resources, kelembagaan dan local phsycal resources. Orientasi ini mengarah pada pengambilan inisiatif - inisiatif yang berasal dari daerah tersebut dalam proses pembangunan untuk menciptakan lapangan kerja baru dan merangsang peningkatan aktivitas perekonomian (Subandi, 2014).

Perencanaan pembangunan ekonomi daerah menjadi sebuah kebutuhan yang absolut karena terkait dengan alokasi distribusi faktor-faktor produksi diantara kawasan -kawasan maupun sektor-sektor perekonomian. Faktor-faktor produksi akan bergerak antara kawasan berdasarkan mekanisme pasar dan mengakselerasi pertumbuhan sektor-sektor ekonomi. Friedman and Alonso, 1964 (dalam
Rahyuda, 2003) menyatakan bahwa daerah memiliki ruang wilayah dan kota, untuk mampu mengintergrasikan kedua hal ini maka dibutuhkan perencanaan pembangunan yang visioner, karena dua hal ini memiliki determinan yang berbeda antara fungsi dan kedudukannya. Dalam perencanaan pembangunan daerah, keduanya diintegrasikan dalam suatu dokumen perencanaan dengan maksud tercapainya kesejahteraan sosial. Sasaran pembangunan hanya mampu terwujud apabila pemerintah daerah mengetahui potensi daerah dan kawasan andalan serta mampu merumuskan strategi kebijakan kebijakan diversifikasi ekonomi regional. Dalam era otonomi seperti saat ini dimana pemerintah daerah memiliki kewenangan yang cukup besar dalam mengelola potensidaerahmaka perencanaan pembangunan yang terintegrasi sangat sesuai untuk mencapai kesesuaian pembangunan yang berkualitas.

\subsection{Etika Bisnis dalam Perspektif Hindu}

Semua agama menyiratkan pesan, ajaran serta nilai-nilai moral yang mampu mempengaruhi tata laksana pemeluknya sesuai dengan iman dan taqwa masing-masing individunya. Dalam Agama Hindu, nilai-nilai tentang tata laksana prilaku yang baik dan buruk yang benar dan yang salah dalam kegiatan bisnis didasarkan atas konsep kemulian manusia sebagai ciptaan Ilahi. Manusia diciptakan dalam bentuk yang paling sempurna dibandingkan dengan semua mahkluk ciptaan lainnya dan terdiri dari raga (jasmani) dan atman (rohani). Dimensi rohani adalah anugerah Tuhan yang diberikan hanya kepada manusia, dengan rohani manusia mendapatkan makna didalam hidupnya (Sarasamuccaya, Sloka 81).

Upaya untuk menelusuri peran nilai-nilai agama Hindu dalam kehidupan global, khususnya entrepreneur perlu diawali dengan memahami makna mendalam dari wahyu Tuhan dalam Veda. Veda sangat kaya akan gagasan maupun nilai-nilai yang dapat pergunakan sebagai referensi dalam bertingkah laku untuk menghadapi tantangan hidup. Penelusuran atas nilai-nilai Hindu melalui pengungkapan makna mendalam dari sabda Tuhan sebagaimana tertulis dalam Kitab Veda, menunjukkan adanya nilai-nilai yang ternyata sangat urgent dalam aktivitas perekonomian. Nilai-nilai tersebut dapat disebut sebagai etika bisnis pelaku 
ekonomi (entrepreneur) menurut perspektif Hindu yakni rasional, kreatif, kerja keras, kerjasama, keselarasan, hidup hemat dan dermawan (Gorda, 1995).

1) Rasional, Kreatif dan Kerja Keras

Kehidupan manusia pada hakekatnya ditentukan dalam tiga perbuatan utama yang disebut dengan istilah Tri Kaya Parisuda terdiri dari Manacika (berpikir), vacika (berkomunikasi) dan kayika (bertingkah laku). Keunggulan manusia dengan makhluk lainnya terletak pada pikirannya, dengan berpikir manusia memperoleh arti dalam hidupnya serta mampu membedakan mana perbuatan yang baik (subhakarma) dan yang buruk (asubhakarma). Dalam menghadapi berbagai pilihan kehidupan pikiranlah yang menjadi penentunya, oleh karena itu pikiran (manah) sebagai episentrum dariaktivitas kehidupan (Sarasamuccaya, Sloka 2 dan 79). Ajaran Hindu menempatkan berpikir (rasio) sebagai kemampuan dan milik manusia yang paling penting dalam kehidupannya. Manusia, tidak terkecuali entrepreneur dinilai dan dihargai oleh orang lain melalui pikirannya. Pedoman utama bagi manusia dalam mengendalikan pikirannya adalah Karma phala Sradha, yakni kenyakinan terhadap konsep imbalan dan hukuman di dunia dan di nirwana (Sarasamuccaya, sloka 74). Ajaran Karma yoga menekankan bahwa hanya dengan bekerja (karma) manusia dapat mencapai tujuan dalam hakekat hidupnya. Tuntutan agama untuk menjadi pekerja yang produktif menyebabkan munculnya takaran keagamaan. Dalam paradigma Hindu seseorang akan memperoleh kesuksesan baik di dunia maupun di nirwana, apabila (1) aktif mengambil prakarsa, bekerja keras, (2) kratif, inovatif, (3) berorientasi pada masa depan. Kutipan itu pula mengingatkan bahwa kerja adalah titah Tuhan sehingga wajib dilaksanakan. Kerja merupakan pengabdian kepada Tuhan yang merupakan pendorong untuk melakukan tindakan yang dibutuhkan dalam menghadapi tantangan global.
2) Kerjasama dan Keselarasan

Kesejahteraan dan kebahagiaan manusia, dalam pandangan Hindu akan tercapai bilamana manusia itu mampu mewujudkan tiga dasar keselarasan yang disebut Tri Hita Karana, yakni Parhyangan (Keselarasan hubungan dengan Tuhan), Pawongan (Keselarasan hubungan dengan sesama) dan Palemahan (Keselarasan hubungan dengan alam). Secara filosopis keselarasan ini bertujuan untuk mencapai Moksartham Jagadhita ca iti Dharma yang memiliki arti tujuan hidup manusia adalah mencapai kesejahteraan jasmani dan kebahagiaan rohani secara selaras serasi dan seimbang (Mantra, 1992).

a) Parhyangan

Setiap individu yang beragama senantiasa berupaya untuk memelihara hubungan yang selaras dengan Tuhan, untuk memelihara keselarasan itu diwujudkan dengan yajnya kepada Tuhan. Mereka yang melaksanakan yajnya sebagai ungkapan tunduk dan hormat kepada Tuhan maka akan mendapatkan Karunia dan perlindungan dari-Nya itulah sebabnya, hubungan yang selaras dengan Tuhan merupakan sumber kebahagiaan yang kekal abadi. Beberapa contoh prinsip etika yang terkai dengan keselarasan manusia dengan Tuhan diantaranya (1) Dharma sebagai inti aktivitas bisnis, (2) Yajnya dan Ngayah (Adhiputra, 2014).

b) Pawongan

Menikmati hidup dengan baik dan berbahagia merupakan dambaan setiap individu dan itu hanya mampu terwujud apabila individu hidup bersama orang lain. Sejak dalam kandungan hingga akhir hayat, manusia memerlukan kehadiran dan pertolongan dari orang lain baik langsung maupun tidak langsung. Setiap individu membutuhkan hasil kerja maupun jasa beragam orang untuk memenuhi segala keinginan dan kebutuhan hidupnya, mulai dari 
sederhana sampai yang paling kompleks sekalipun. Ajaran Karma yoga meminta agar setiap rumah tangga termasuk rumah tangga dalam ilmu ekonomi baik mikro maupun makro melaksanakan manusa yajnya, yakni korban suci kepada sesama manusia yang diwujudkan melalui upacara keagamaan, memberi pertolongan kepada yang membutuhkan dan saling menghormati antar sesama (Mantra, 1989). Dalam Regveda VII.32.8 tertulis bahwa Sang Hyang Widhi Wasa akan memberi Karunia kepada individu yang selalu berbuat baik, juga dinyatakan bahwa Dewa Asvina akan memberikan berkah -Nya kepada mereka yang selalu berusaha untuk menciptakan korelasi yang selaras diantara sesama manusia. Dalam kaitannya dengan aspek ekonomi khususnya para entrepreneur, kekayaan suatu firm hendaknya didayagunakan sebagai wahana untuk mempererat tali persahabatan dan persaudaraan (Regveda, VII.72.2), Hal ini menyiratkan bahwa kekayaan dan kemajuan firm adalah keberuntungan kolektif, artinya keberhasilan firm merupakan hasil kerjasama dan hubungan yang selaras diantara entrepreuner, karyawan, konsumen maupun pihak terkait lainnya. Keberhasilan seorang entrepreneur bukanlah prestasi individu melainkan prestasi secara kolektif oleh karena itu, mereka juga harus menikmati profit firm. Di dalam membagikan profit seorang entrepreneur harus jujur serta loyal terhadap kesepakatan akan janji yang sudah dibuat sebelumnya, inilah interpretasi dari menggunakan kekayaan dan kemajuan firm untuk keuntungan bersama demi mempertebal tali persahabatan antara entrepreneur dengan stakeholders.

c) Palemahan

Alam semesta beserta isinya merupakan ciptaan Tuhan yang dalam konsep Hindu terdiri atas lima unsur (Panca Maha Bhuta) terdiri dari : Udara (bayu), air (apah), api (teja), tanah (pertiwi) dan udara (akasa). Bhuta memiliki dua sifat yaitu positif dan negatif. Bhuta dalam Veda adalah kekuatan negatif (Asuri Sampat) yang selalu mengganggu hidup manusia, sifat yang demikian ini bertentangan dengan sifat dewa (Daivi Sampat) yang selalu memelihara dan memberi kebaikan bagi kehidupan manusia (Puja, 1985). Tanpa kelima unsur dalam Panca Maha Bhuta itu, manusia tidak dapat hidup ini menandakan bahwa manusia wajib hukumnya untuk menghargai dan menghormati segala sumber kehidupan. Ajaran Hindu meminta agar setiap rumah tangga mengimplementasikan pelaksanaan Bhuta Yajnya yakni korban suci yang tulus iklas bagi alam sekitar. Di dalam Veda Smrti Manawadharmasastra (III.89-285) dijelaskan bahwa untuk memperoleh kebahagiaan, setiap hari umat Hindu wajib melaksanakan panca yajnya, salah satu dari kelimanya adalah bhuta yajnya. Melalui bhuta yajnya, umat Hindu yakin bahwa bhuta dapat dibujuk dan ditentramkan sehingga tidak mengeluarkan sifat-sifat negatifnya. Pengejawantahan konsep ini dalam etika bisnis diantaranya : (1) melakukan aktivitas atau usaha ekonomi (bisnis) yang tidak merusak maupun mencemari lingkungan, (2) menggunakan sumber daya atau piranti pendukung yang ramah terhadap lingkungan, (3) tidak mengeksploitasi lingkungan secara berlebihan, (4) pembangunan (aktivitas) ekonomi yang berwawasan lingkungan.

Kerjasama dan keharmonisan korelasi dengan Tuhan, dengan sesama dan dengan alam sekitar merupakan saripati ajaran Tri Hita Karana. Ajaran ini juga merupakan ajaran yang sesuai dengan salah satu ciri manusia modern, yakni 
kesediaan dan kemampuan untuk bekerja secara kolektif (Myrdal, 1968). Kesesuaian antara Tri Hita Karana dengan ciri manusia modern dan modernisasi menunjukkan bahwa agama Hindu memberi kontribusi signifikan bagi membentukan manusia yang berwatak modern yang siap menjadi backbone pembangunan modern.

3) Hidup Hemat dan dermawan

Keinginan dalam diri manusia mendorongnya untuk melakukan suatu aktivitas, dalam kenyataannya hampir tidak ada aktivitas tanpa didasari oleh keinginan. Manusia memerlukan sejumlah artha sebagai wahana dalam pemenuhan keinginan dan dharma sebagai pengendali dari keinginan tersebut. Dharma diperlukan sebagai upaya menghindarkan terjadinya distorsi diantara sesama manusia dalam pemenuhan keinginan parsialnya (Manavadharmasastra, II.4). Agama Hindu tidak merintangi umatnya dalam mengejar artha sepanjang hal tersebut dilakukan sesuai dharma. Umat juga didorong untuk melakukan reinvestasi dalam rangka mengkapitalisasi kekayaan, disarankan reinvestasi dilakukan dengan dua cara, yakni dengan menyisihkan perolehan dan menabung. Dalam hal ini tampak Hindu menekankan pula urgensi suatu kapitalisasi modal sebagai sumber daya dalam rangka menunjang aktivitas ekonomi dan juga mengijinkan individu untuk mengejar profit, seperti yang tertuang dalam Sarasamuccaya, sloka 263 : artha yang diperoleh berdasarkan dharma adalah laba, sedangkan yang diperoleh dengan jalan adharma adalah noda. Dalam konteks ilmu ekonomi, pertumbuhan ekonomi ditentukan oleh volatilate saving dan invesment (Harrod Domar), jadi apabila ajaran Hindu mengenai reinvestasi dikorelasikan dengan teori Harrod Domar tersebut maka dapat disimpulkan bahwa Hindu tidak menolak semangat investasi baik yang bersumber dari profit maupun tabungan. Ajaran Hindu menekankan pentingnya individu memelihara equilibrium diantara dharmartha, kamartha dan vivirdhayet. Hal ini mengandung makna bahwa individu wajib memelihara keseimbangan pemenuhan kebutuhan spiritual keagamaan dengan kebutuhan duniawi dan kesimbangan di antara keinginan untuk mencari artha dengan melaukan yajnya (dana punia).

\subsection{Urgensi Entrepreneurship dalam Pembangunan Ekonomi}

Seorang entreprenuer dengan spirit wira (pahlawan/berani) dalam menciptakan value edit dengan jalan mengkolaborasikan resources (Entrepreneurship) melalui metode baru dan berbeda untuk memenangkan persaingan, memiliki peran yang sangat strategis dalam pembangunan ekonomi suatu negara (Szabo, 2012), mereka memiliki kontribusi yang signifikan dalam penyerapan tenaga kerja, inovasi, produksi dan pertumbuhan. Aktivitas entrepreneurial wajib untuk menjadi ruang lingkup bagi inovasi produk maupun sistem sehingga produktivitas menjadi meningkat untuk menjadi lokomotif penggerak pertumbuhan dan pembangunan ekonomi. Kemampuan entrepreneur yang inovatif mampu melakukannya dengan optimal. Entrepreneur ini memiliki skill dan knowledge untuk dapat menciptakan inovasi-inovasi baru. Peluang entreprenuer yang inovatif ini dapat ditiru oleh para individu yang memliki keahlian dalam bidangnya masing-masing serta mampu mentransformasikan produk yang inovatif tersebut menjadi produk yang dapat dikomersialisasikan sehingga mampu memberikan kontribusi dalam pertumbuhan maupun pembangunan ekonomi.

Penelusuran atas nilai-nilai Hindu melalui pengungkapan arti mendalam dari sabda Tuhan sebagaimana tertulis dalam kitab Veda menunjukkan adanya nilai-nilai yang ternyata sangat urgent dalam aktivitas perekonomian. Nilai-nilai tersebut dapat diistilahkan sebagai etika bisnis entrepreneur dalam konsep Hindu, yakni rasionalitas, kreatifitas, kerja keras, kerjasama, keselarasan, serta hidup hemat dan dermawan (Gorda, 1995). Semua nilai ini adalah nilai-nilai yang dibutuhkan dan menjadi syarat bagi pembangunan ekonomi umumnya dan pemunculan entrepreneur baru secara spesifik.

Kitab Veda mengungkap tentang nilai-nilai 
yang menyangkut problematika kehidupan manusia di alam dunia saat ini, dengan demikian ada koherensi antara nilai-nilai Hindu dengan nilai-nilai yang dipersyaratkan bagi pembangunan ekonomi, karena paradigma Hindu mendukung dan tidak menghambat realisasi nilai-nilai yang diperlukan dalam pembangunan ekonomi. Nilai-nilai tersebut dikenal dan dipahami oleh para entrepreneur sejak masih kanak-kanak, melalui cerita keagamaan yang mereka dengar, baca dan saksikan dalam pertunjukan khas yang menjadi local genius melalui upacara keagamaan.

Selama proses pembangunan ekonomi bergulir, maka berbagai peluang baru akan terbuka, tergantung bagaimana setiap insan mampu membaca, menangkap peluang tersebut. Letak keberhasilan pembangunan ekonomi sebagai kegiatan secara simultan untuk memanfaatkan berbagai peluang yang bermunculan adalah hasil dari kerja keras secara kolektif dengan berbagai pihak terkait. Spirit kerja keras tersebut bersumber pada interaksi entrepreneur Bali dengan Tuhan dan Atman leluhur yang diwujudkan dalam berbagai aktivitas keagamaan. Aktivitas keagamaan ini merupakan pemahaman dan penghayatan terhadap nilai-nilai agama serta pelaksanaan yajnya, selain itu upacara keagamaan memiliki daya ungkit yang signifikan terwujudnya solidaritas sosial yang tinggi.

Usaha peningkatan kualitas aktivitas spiritual keagamaan termasuk nilai-nilai (ethics) dalam bisnis bagi seorang entrepreneur perlu dilakukan secara holistik, dengan adanya peningkatan kualitas tindakan keagamaan tersebut maka akan mampu meningkatkan mutu kerja keras kolektif pada setiap insani dengan demikian ia akan mampu mengakselerasi peluang yang maupun merebut peluang yang baru. Peningkatan kualitas aktivitas keagamaan akan menjadi daya ungkit untuk meningkatkan dinamika struktur pembangunan ekonomi Bali yang berpijak pada sektor pariwisata budaya, ini berarti akan semakin banyak muncul peluang bisnis baru bagi entrepreneur maupun masyarakat Bali untuk memberikan kontribusi yang signifikan bagi pembangunan ekonomi Bali.

\section{PENUTUP}

Secara filosofis dalam ruang etis-teologis Kitab suci Veda (Agama Hindu) memberikan petunjuk yang sangat berharga kepada umat khususnya umat Hindu yang ingin terjun kedalam aktivitas ekonomimenjadientrepreneur tentang bagaimana aturannya mereka bersikap santun sebagai seorang entrepreneur dalam mengelola usahanya. Petunjuk yang dimaksud adalah, pertumbuhan ekonomi pada umumnya maupun pertumbuhan suatu firm pada khususnya menghendaki dari kesediaan manusia untuk mencurahkan pikiran (rasionalitas dan kreatifitas) kepada peningkatan produktifitas, yang mana hal itu hanya mampu dicapai apabila diiringi oleh kerja keras, kerjasama, keselarasan hubungan dengan berbagai pihak yang terkait dengan firm, hidup hemat, dermawan jujur dan setia terhadap kesepakatan dalam hubungan bisnis. Didalam Veda berbagai nilai (ethics) yang dipandang sangat dibutuhkan bagi penumbuhan, pengembangan sekaligus pedoman hidup bagi entrepreneur dalam menjalankan aktivitas usahanya yang hilirnya akan berkontribusi terhadap pertumbuhan maupun pembangunan ekonomi daerah. 


\section{DAFTAR PUSTAKA}

Acs, Z, J,.2006. How is Entrepreneurship Good for Economic Growth? Innovation: Technology, Governance, Globalization 1 (1), pp 97-107

Aidis, R.2003. Entrepreneurship and Economic Transition. Tinbergen Institue Discussion Paper. (http:www.tinbergen.nl)

Abdurrahman. 1994. Beberapa Catatan Tentang Aspek Religius Ajaran Hindu dan Pembangunan (M.Masyur Amin, ed. : Moralitas Pembangunan : Perspektif Agama-agama di Indonesia). LKPSM, Yogyakarta

Adhiputra.2014. Prinsip Etika Dalam Bisnis Hindu (Fenomena Praktik Bisnis di Era Globalisasi), Denpasar : Universitas Mahendradatta

Badan Pusat Statistik Provinsi Bali. 2012. Bali Dalam Angka. Denpasar Badan Pusat Statistik Provinsi Bali. 2015. Bali Dalam Angka. Denpasar Badan Pusat Statistik Provinsi Bali. 2017. Bali Dalam Angka. Denpasar

Bellah, Robert n. 1992. Religi Tokugawa : Akar-Akar Budaya Jepang. (Alih Bahasa : Wardah Hafidz dan Wiladi Budiharga). Diterbitkan atas Kerjasama Karti Sarana dengan Gramedia Pustaka Utama, Jakarta

Biro Humas Prov. Bali.2012. Buku Saku Program Pembangunan Bali Mandara. Setda Provinsi Bali Blundel,R.2009. Book Review : Entrepreneurship, Growth and Public Policy : Prelude to a Knowledge Spillover Theory of Entrepreneurship . International Journal of Entrepreneurial Behaviour and Research. 15 (3) : 309-312

Deliarnov. 2007. Perkembangan Pemikiran Ekonomi. Jakarta : PT Raja Grafindo Persada

Geertz. 1977. The Religion of Java. The Press, New York USA

Gorda G.N, 1995. Nilai-Nilai Agama Hindu dan Etika Ekonomi Wirausahawan Bali. Disertasi Universitas Airlangga

Hulaimi, Sahri dan Huzaini. 2017. Etika Bisnis Islam dan Dampaknya Terhadap Kesejahteraan Pedagang Sapi. Jurnal Ekonomi Bisnis Islam. Volume 2, Nomor 1, Januari-Juni 2017, pp 17-32.

Mantra,I.B. 1992. Tata Susila Hindu Dharma. Denpasar : Upada Sastra

Myrdal, Gunnar.1968. Asian Drama ; An Inquiry into The Proverty of Nations. (Diterjemahkan dalam Basis. XVI No. 3) Panheon, New York.

Rahyuda, Ketut. 2003. Strategi Pembangunan Provinsi Bali. Dewan Harian Daerah ISEI cabang Denpasar

Sanjaya, Krisna. 2018. Metode Mudah Memahami Pengantar Ekonomi Makro. Denpasar : Penerbit : CV. Sastra Darmastuti

Subandi. 2014. Ekonomi Pembangunan. Bandung : Penerbit Alfabeta

Szabo,K. Zsusanna, Emilia Herman. 2012. Innovative Entrepreneurship for Economic Development in EU. Procedia Economics and Finance (3) 268-275. www.sciencedirect.com

Todaro, M., Smith. C.S. 2004. Pembangunan Ekonomi di Dunia Ketiga. Jakarta : Penerbit Erlangga

Puja, G. 1985. Pengantar Agama Hindu Untuk Perguruan Tinggi, Jakarta : MayasariPindyck, R.S., and Rubinfeld, D.L., 2003, Microeconomics, Sixth Edition, Prentice Hall Inc., New Jersey. 